\title{
Reliability and validity of a fruit and vegetable self-efficacy instrument for secondary-school students in the Netherlandst
}

\author{
Rienke Bannink ${ }^{1, *}$ and Jaap J van der Bij $\left.\right|^{2}$ \\ ${ }^{1}$ Institute of Nursing Studies, Faculty of Health Care, University of Applied Sciences Utrecht, Bolognalaan 101, \\ 3508 AD Utrecht, The Netherlands: ${ }^{2}$ Masters Advanced Nursing Practice and Physician Assistant, Faculty of \\ Health, Welfare and Sports, Inholland University of Applied Sciences, Amsterdam, The Netherlands
}

Submitted 19 March 2010: Accepted 7 October 2010: First published online 6 January 2011

\begin{abstract}
Objective: To develop a 'fruit self-efficacy' (FSE) instrument and a 'vegetable selfefficacy' (VSE) instrument for secondary-school students in the Netherlands and to test the reliability and validity of these instruments.

Design: Methodological research.

Setting: Seven secondary schools in the Netherlands.

Subjects: Students (11-19 years of age) completed the two instruments in the classroom ( $n$ 466). Out of the original subject group, 106 students completed the instruments a second time.

Results: The relevance of the twenty-two items of the two developed instruments was evaluated on two occasions by four experts. This procedure resulted in seventeen items for both instruments. Further analysis was carried out on the basis of the secondary-school students' answers. Factor analysis identified two unidimensional instruments. Cronbach's $\alpha$ was 0.94 for the FSE instrument and 0.95 for the VSE instrument. The intra-class correlation coefficient between the test and the retest for both instruments varied between 0.33 and $0.84(P<0.05)$, depending on how the tests were taken (during class or on the student's own initiative), and the order in which the tests were completed (started or finished with a different instrument used for similar research). The correlation between FSE and fruit consumption was $0 \cdot 41(P<0 \cdot 01)$ and between VSE and vegetable consumption was $0 \cdot 32(P<0 \cdot 01)$.

Conclusions: The two instruments are sufficiently reliable and valid to assess the FSE and VSE of secondary-school students in the Netherlands. Further research, in which the predominant ethnic minorities in the Netherlands are sufficiently represented, is required to confirm this conclusion.
\end{abstract}

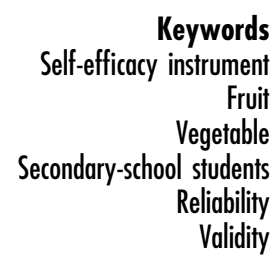

The number of secondary-school students with overweight and obesity is increasing worldwide ${ }^{(1)}$. During the years 2002-2004, in a survey of 15-year-old Dutch students, $20 \cdot 1 \%$ of female and $16 \cdot 8 \%$ of male students suffered from overweight, whereas $4.7 \%$ and $3.9 \%$, respectively, were diagnosed with obesity ${ }^{(2)}$. Overweight and obesity in young people are diagnosed using the international BMI curves for age and sex ${ }^{(3)}$.

The increase in overweight and obesity is a worrying development because overweight, and particularly obesity, can have detrimental effects both at an early age and in the long term. Effects at a young age may include psychosocial stress, low self-esteem, skeletal abnormalities, fatigue and glucose intolerance. In the long term, the

$\dagger$ The research was conducted at the University of Utrecht, Faculty of Medicine, Department of Nursing Science, Utrecht, The Netherlands. consequences may be CVD, diabetes, arthritis, high blood pressure and cancer ${ }^{(4)}$.

Overweight and obesity are caused by insufficient physical activity and unhealthy dietary habits in more than $90 \%$ of cases ${ }^{(5,6)}$. One of the most unfavourable trends in the dietary behaviour of secondary-school students, a trend that exacerbates the problem of overweight, is the decreasing consumption of fruit and vegetables $^{(6)}$. Less than half of secondary-school students in the Netherlands consume the recommended daily amount of fruit and vegetables ${ }^{(7)}$. Habits that develop during the secondary-school phase have an important role in the development of health-related behaviour in adulthood $^{(8)}$. Cognitive motivational processes strongly influence secondary-school students' eating habits, whereas younger children choose foods mainly on the basis of their preferences $^{(9)}$. 
Self-efficacy has a central role in the cognitive regulation of motivation ${ }^{(10)}$. Self-efficacy proves to be an important predictor of many health-related phenomena, such as smoking, weight control, diet, alcohol use and AIDS prevention ${ }^{(11-17)}$. The term 'self-efficacy' was used for the first time in 1977 by the American psychologist Albert Bandura ${ }^{(18)}$. Bandura described self-efficacy as '...people's judgement of their capabilities to organise and execute courses of action required to attain designated types of performances, ${ }^{, 11)}$. This description shows that people's self-efficacy is not of a general nature, but is related to specific situations ${ }^{(19)}$. A person can judge himself as competent to eat fruit at home, whereas he may not judge himself as competent to eat fruit at school.

The higher the level of self-efficacy, the higher the likelihood that people will be able to display the desired behaviour $^{(11)}$. The level of self-efficacy can be influenced by targeted interventions that are developed on the basis of the theoretical background. However, before interventions can be developed to increase self-efficacy with regard to fruit and vegetable consumption, it is important to know whether self-efficacy is actually a predictor of fruit and vegetable consumption among secondaryschool students. A literature review proves that this cannot be ascertained yet. A significant positive relationship was found in three ${ }^{(20-22)}$ out of five studies ${ }^{(20-24)}$ among secondary-school students in which the relationship between self-efficacy and consumption of fruit and vegetables was studied. Neumark-Sztainer et al. ${ }^{(21)}$ are the only ones reporting a correlation coefficient. Between the 'self-efficacy for making healthy dietary choices' and 'fruit and vegetable consumption', a correlation of $0 \cdot 18$ was found.

Reliable and valid instruments are required to expand research on self-efficacy as a predictor of fruit and vegetable consumption and thus gain more insight into the relevance of developing interventions for increasing selfefficacy. No instruments were found in the literature for measuring self-efficacy for vegetable consumption among Dutch secondary-school students, and only one instrument was found for measuring the self-efficacy for fruit consumption. This instrument was made up of a single item $^{(24)}$. Thus, valid and reliable instruments for measuring 'fruit self-efficacy' (FSE) and 'vegetable self-efficacy' (VSE) among secondary-school students are lacking in the Netherlands. Because of the specificity of the selfefficacy concept, separate instruments must be developed for FSE and $\mathrm{VSE}^{(25)}$.

The first aim in the present research was the development of two measurement instruments for the Dutch situation: one instrument to measure FSE among secondary-school students in the Netherlands, another to measure VSE among this target group. The second aim was to test the reliability and validity of the developed instruments.

\section{Method}

\section{Design}

The present research can be characterised as methodological research ${ }^{(26)}$. The Lynn procedure ${ }^{(27)}$ was followed in the development of the two self-efficacy instruments to achieve sufficient content validity. This procedure entailed that the dimensions of the concept that was to be measured were identified in the development phase. Items were then formulated for these dimensions. In the final phase, the content validity of the items and instruments were assessed.

After the instruments were developed, both instruments were assessed for construct validity (using factor analysis), internal consistency, temporal stability and predictive validity.

\section{Developing the instruments}

Dimensions of self-efficacy

Bandura $^{(28)}$ describes how self-efficacy can be measured in three dimensions, namely 'generality', 'strength' and 'level'. 'Generality' refers to the degree to which selfefficacy is positively related within a behavioural domain, between different behavioural domains or in relation to time ${ }^{(13)}$. 'Strength' refers to how certain a person is of being able to perform a certain activity ${ }^{(28)}$. 'Level' refers to the number of activities with an increasing difficulty level that a person thinks he/she can carry out ${ }^{(28)}$. All three dimensions were measured in the present research, whereby the dimension 'generality' was measured within and between the behavioural domain 'fruit' and the behavioural domain 'vegetables'.

To ensure a reliable assessment of the 'strength' dimension, the secondary-school students scored their own self-efficacy on a 4-point Likert scale. An asymmetrical 4-point scale was chosen for the present research: 1 = 'uncertain', 2 = 'almost certain', $3=$ 'certain', $4=$ 'very certain'. This simple scale was chosen because of the target group of secondary-school students who could have poor reading skills. Furthermore, this asymmetrical answer scale has relatively more positive answers. Research has shown that, when people are asked to grade their self-efficacy, they are more likely to think that they 'will' be able to do something rather than that they 'will not'(29).

In English, self-efficacy items are typically formulated with the phrase 'How confident are you at...'. In Dutch, various formulations are used, because the Dutch language does not have an exact equivalent of the concept 'confident'. Commonly used phrases in the Netherlands are: 'I think I'm able to...', 'Do you succeed in...', 'To what extent do you estimate it realisable to...', 'I'm sure/certain that I can...', or 'I'm convinced I can..., ${ }^{(30)}$. Six secondaryschool students (preparatory secondary vocational education) were asked for their preference. The phrase 'I'm certain that I can...' was chosen on this basis. 


\section{Generating items}

When measuring self-efficacy, difficult situations for the students to eat fruit or vegetables must be included in the instrument to ensure a reliable assessment of the dimension 'level'. Sufficient difficult situations must be included to preclude ceiling effects ${ }^{(31)}$. To reliably assess the dimension 'generality', the behavioural factors related to the behavioural domain 'fruit' and the behavioural domain 'vegetables' must be included ${ }^{(31)}$, such as buying and eating fruit and vegetables.

Two existing American instruments were used to identify behavioural factors and difficult situations that have a role in fruit and vegetable consumption ${ }^{(32,33)}$. On the basis of these instruments, twenty-three 'fruit items' and twentythree 'vegetable items' were selected. To gain more insight into the difficult situations for secondary-school students in the Netherlands, these items were assessed in a pilot study for twenty-three secondary-school students using an opportunity sample (average age $=14 \cdot 6$ (SD 1.7) years) These students were asked to score the difficulty of carrying out the behaviour for each item using a 5-point Likert scale, from $1=$ easy to $5=$ difficult. One item was then removed from each of the instruments for which all the respondents gave the answer 'easy'. These two items had no discriminatory value.

Students were also asked to make suggestions for improvement of each item, and they could indicate whether items were lacking. Subsequently, on the basis of the students' feedback about the Dutch situation, three fruit and two vegetable items were removed, three fruit and two vegetable items were added and five fruit and six vegetable items were modified, as a result of which both the FSE and VSE instruments consisted of twenty-two items.

\section{Assessing content validity}

Thirteen Dutch and Belgian researchers were approached who had all published on self-efficacy in relation to school students' dietary habits. These experts were asked to score the twenty-two items of the FSE instrument and the twentytwo items of the VSE instrument for relevance in relation to the concept of 'self-efficacy' on a 4-point scale, from $1=$ not relevant to $4=$ very relevant ${ }^{(27)}$. The experts were also able to make suggestions for improvement of each item, and they could indicate whether items were lacking.

\section{Testing the instruments}

\section{Research participants}

Twenty-three secondary schools throughout the Netherlands were approached to participate in the research. Seven schools were willing to cooperate, and were located in four cities in the middle and one city in the south of the Netherlands. The size of the schools ranged from about 650 students to 1850 students.

Eight teachers at the seven secondary schools were asked to participate. Students at these schools were recruited using an opportunity sample. The teachers were able to indicate which class or classes they considered most suitable for participation. This increased the chances of an individual teacher being willing to participate. The research strove for as much variety as possible in class levels and years. A total of twenty-one classes participated. Both self-efficacy instruments were administered among these secondaryschool students. The students simultaneously completed an 'alcohol self-efficacy' instrument for a similar research project. The order in which the students completed the three self-efficacy instruments varied. Students from four teachers started with the FSE and VSE instruments, students from the other four teachers started with the 'alcohol selfefficacy' instrument. This was to reduce the influence of completion order on the results; the students might, after completing one or two instruments, become less motivated to fill in a third.

The determining factor for the sample size was the factor analysis within the framework of the construct validation. The common rule of thumb, 'at least ten times as many respondents as items', was applied ${ }^{(34)}$. Because the final versions of the two self-efficacy instruments consisted of seventeen items each (see 'Content validity' under 'Results' section), the minimum sample size was 170 students.

\section{Fruit and vegetable consumption questionnaire}

Fruit and vegetable consumption was measured to determine the predictive validity of the self-efficacy instruments. Consumption was measured by questioning students on how often they ate fruit and vegetables during a normal week. The seven response options of both questions ranged from 'never' to 'more than once per day'. These two questions were taken from the international questionnaire prepared by the Health Behaviour in School-aged Children organisation.

The test-retest reliability of the consumption questions was assessed in another study and was 0.68 for fruit and 0.59 for vegetables. The correlation between the above-mentioned questions and a $7 \mathrm{~d}$ diary was $0 \cdot 34$ for fruit and $0 \cdot 48$ for vegetables. A detailed description of the reliability and validity can be read elsewhere ${ }^{(35)}$.

\section{Procedure}

The researcher and/or the students' teacher was present while the instruments were being completed in the classroom. Teachers could choose between a written and a digital version. This was to increase the chance of teachers participating.

To determine the temporal stability of both self-efficacy instruments, after $28 \mathrm{~d}$ the students were asked to complete the self-efficacy instruments again within a period of 2 weeks. The students of four classes completed the instruments in the classroom a second time. The students in the other seventeen classes were allowed to decide for themselves where and when they would complete the 
instruments digitally, thus limiting the amount of time these schools had to invest.

\section{Ethical aspects}

All secondary-school students and the parents of students up to the age of 16 years received written information about the research. They could decline to cooperate before the research started. Students and parents were reassured that the anonymity of the students would be guaranteed. The Medical Ethical Assessment Committee of Utrecht University Medical Center gave permission for conducting the present research.

\section{Statistical analysis}

All data were analysed using the Statistical Package for the Social Sciences statistical software package version 16.0 (SPSS Inc., Chicago, IL, USA).

\section{Content validity}

Both the 'item-content validity index' (I-CVI) and the 'scale-content validity index' (S-CVI) were calculated. The I-CVI was determined by the proportion of experts who assessed an item as content valid (score: 3 or 4). The $\mathrm{S}$-CVI was determined by the average proportion of items that scored 3 or $4^{(36)}$.

\section{Construct validity}

Data were analysed using the Principal Components Analysis (PCA). The following criteria were used for determining the number of factors: factors must have an eigenvalue of $>1 \cdot 00$; factors are included up to the point that their eigenvalue curve flattens (calculated with a screeplot) ${ }^{(34)}$; and factor loadings must have an absolute value of $>0 \cdot 40^{(26)}$.

\section{Internal consistency}

Cronbach's $\alpha$ was calculated to determine internal consistency.

\section{Temporal stability}

Stability was determined using the single-measure intraclass correlation coefficient (ICC; one-way random model). According to Cicchetti's guidelines ${ }^{(37)}$, an ICC is poor when it has a value $<0 \cdot 40$, fair when it is between 0.40 and 0.60 , good $>0 \cdot 60$ and excellent $>0 \cdot 75$.

\section{Predictive validity}

Spearman's rank correlation was used to calculate the correlations between self-efficacy and consumption, as measured at the ordinal level.

\section{Results}

\section{Content validity}

Four out of thirteen experts scored the relevance of the items. According to Lynn's method ${ }^{(27)}$, if there are four experts, then all of them must score an item as 3 or 4 to be able to class that item as content valid. On this basis, eight items in the FSE instrument and seven items in the VSE instrument could not be classed as content valid. Of these, six items were removed from both instruments that, according to the experts, were not relevant to fruit or vegetable consumption, or were not related to self-efficacy. The other three non-content valid items were reviewed, and three items were added to each instrument on the basis of the experts' suggestions. Both instruments were then sent to the experts for re-assessment. After this re-assessment, both instruments still contained two items that could not be classed as content valid. The experts indicated that these two items were not relevant to fruit and vegetable consumption and these items were removed. The S-CVI of both instruments at the end of this procedure was $1 \cdot 0$, which is a

Table 1 Demographic characteristics of the research participants for time 1 ( $n$ 466) and time 2 ( $n$ 106)

\begin{tabular}{|c|c|c|c|c|}
\hline \multirow[b]{2}{*}{ Characteristics } & \multicolumn{2}{|c|}{ Time 1} & \multicolumn{2}{|c|}{ Time 2} \\
\hline & $n$ & $\%$ & $n$ & $\%$ \\
\hline \multicolumn{5}{|l|}{ Sext } \\
\hline Male & 235 & $50 \cdot 6$ & 54 & $50 \cdot 9$ \\
\hline Female & 229 & $49 \cdot 4$ & 52 & $49 \cdot 1$ \\
\hline \multicolumn{5}{|l|}{ Age (years)† } \\
\hline 11 & 1 & $0 \cdot 2$ & 0 & 0 \\
\hline 12 & 42 & $9 \cdot 4$ & 12 & $11 \cdot 3$ \\
\hline 13 & 121 & $26 \cdot 9$ & 30 & $28 \cdot 3$ \\
\hline 14 & 113 & $25 \cdot 2$ & 19 & $17 \cdot 9$ \\
\hline 15 & 67 & $14 \cdot 9$ & 19 & $17 \cdot 9$ \\
\hline 16 & 52 & $11 \cdot 6$ & 16 & $15 \cdot 1$ \\
\hline 17 & 40 & 8.9 & 8 & $7 \cdot 5$ \\
\hline 18 & 12 & $2 \cdot 7$ & 1 & $0 \cdot 9$ \\
\hline 19 & 1 & $0 \cdot 2$ & 1 & 0.9 \\
\hline \multicolumn{5}{|l|}{ School levelt } \\
\hline PSVE & 119 & $25 \cdot 7$ & 51 & $48 \cdot 1$ \\
\hline PSVE/SGSE & 64 & $13 \cdot 8$ & 17 & $16 \cdot 0$ \\
\hline SGSE & 72 & $15 \cdot 5$ & 8 & $7 \cdot 5$ \\
\hline SGSE/PUE & 80 & $17 \cdot 2$ & 13 & $12 \cdot 3$ \\
\hline PUE & 129 & $27 \cdot 8$ & 17 & $16 \cdot 1$ \\
\hline \multicolumn{5}{|l|}{ Ethnic groupt } \\
\hline Dutch & 373 & $80 \cdot 7$ & 86 & 81.9 \\
\hline Surinamese & 7 & 1.5 & 1 & $1 \cdot 0$ \\
\hline Moroccan & 18 & $3 \cdot 9$ & 4 & $3 \cdot 8$ \\
\hline Turkish & 2 & $0 \cdot 4$ & 1 & $1 \cdot 0$ \\
\hline Antillean or Aruban & 3 & $0 \cdot 6$ & 0 & $0 \cdot 0$ \\
\hline Other & $59 \ddagger$ & $12 \cdot 8$ & $13 \S$ & $12 \cdot 3$ \\
\hline \multicolumn{5}{|l|}{ Fruit consumptiont } \\
\hline Never & 15 & $3 \cdot 2$ & 4 & $3 \cdot 8$ \\
\hline Less than once weekly & 31 & $6 \cdot 7$ & 2 & $1 \cdot 9$ \\
\hline Once weekly & 57 & $12 \cdot 3$ & 10 & $9 \cdot 4$ \\
\hline $2-4 \mathrm{~d} /$ week & 130 & $28 \cdot 0$ & 34 & $32 \cdot 1$ \\
\hline $5-6 \mathrm{~d} /$ week & 61 & $13 \cdot 1$ & 15 & $14 \cdot 2$ \\
\hline Every day, once daily & 100 & $21 \cdot 6$ & 25 & $23 \cdot 6$ \\
\hline Every day, more than once & 70 & $15 \cdot 1$ & 16 & $15 \cdot 1$ \\
\hline \multicolumn{5}{|l|}{ Vegetable consumptiont } \\
\hline Never & 4 & $0 \cdot 9$ & 0 & $0 \cdot 0$ \\
\hline Less than once weekly & 0 & 0 & 0 & $0 \cdot 0$ \\
\hline Once weekly & 8 & $1 \cdot 7$ & 5 & $4 \cdot 7$ \\
\hline $2-4 \mathrm{~d} /$ week & 68 & $14 \cdot 7$ & 11 & $10 \cdot 4$ \\
\hline $5-6 \mathrm{~d} /$ week & 130 & $28 \cdot 0$ & 22 & $20 \cdot 8$ \\
\hline Every day, once daily & 216 & $46 \cdot 6$ & 56 & $52 \cdot 8$ \\
\hline Every day, more than once & 38 & $8 \cdot 2$ & 12 & $11 \cdot 3$ \\
\hline
\end{tabular}

PSVE, preparatory secondary vocational education; SGSE, senior general secondary education; PUE, pre-university education.

tSome items are not equal to $n 466$ or $n 106$ because of missing values. ‡Forty ethnic groups.

$\S$ Eleven ethnic groups. 
reliable content validity score ${ }^{(36)}$. The final version of each instrument contained seventeen items.

\section{Results of testing the instruments}

Research participants

In the present research, 466 students took part (Table 1). Only one student did not take part because his parents objected to his participation.

The students were 11-19 years of age, and 50.6\% were male students. All secondary-school levels recognised in the Netherlands were included. The majority of respondents were ethnic Dutch $(80 \cdot 7 \%)$. This percentage is in line with the percentage of ethnic Dutch secondary-school students in the 2007-2008 school year (79.2\%). However, other widely represented ethnic minorities in the Netherlands were strongly under-represented in this sample. These include Surinamese, Moroccan, Turkish, Antillean and Aruban students ${ }^{(38)}$.

Both self-efficacy instruments were completed a second time by 106 out of 466 students. Fifty-eight students completed the instruments again in the classroom, forty-eight students completed them at their own initiative.

\section{Construct validity}

The PCA of the FSE and VSE instruments produced an eigenvalue of $>1 \cdot 00$ for the first two factors (Tables 2

Table 2 Factor structure and item scores for the fruit self-efficacy instrument

\begin{tabular}{|c|c|c|c|c|}
\hline \multirow{2}{*}{$\begin{array}{l}\text { Item } \\
\text { I am certain that I can... }\end{array}$} & \multicolumn{2}{|c|}{ Loadings } & \multirow[b]{2}{*}{ Mean scoret } & \multirow[b]{2}{*}{ SD } \\
\hline & Factor 1 & Factor 2 & & \\
\hline 1. ... eat fruit as a snack & 0.83 & $-0 \cdot 14$ & $3 \cdot 46$ & $0 \cdot 81$ \\
\hline 2. ... eat fruit if I have to prepare it myself & 0.80 & -0.05 & $3 \cdot 38$ & 0.91 \\
\hline 3. ... eat fruit during lunch & 0.80 & $-0 \cdot 19$ & $3 \cdot 29$ & 0.92 \\
\hline 4. ... eat fruit if my parents are not there & $0 \cdot 78$ & -0.28 & $3 \cdot 61$ & 0.71 \\
\hline 5. ... eat fruit as a snack instead of a biscuit & 0.77 & $0 \cdot 46$ & $2 \cdot 87$ & $1 \cdot 14$ \\
\hline 6. ... eat fruit during a meal at home & $0 \cdot 74$ & -0.26 & $3 \cdot 33$ & 0.92 \\
\hline 7. ... eat fruit during breakfast & 0.74 & -0.24 & $3 \cdot 07$ & $1 \cdot 11$ \\
\hline 8. ... eat fruit even if no one else is eating fruit & 0.73 & $-0 \cdot 14$ & $3 \cdot 42$ & 0.82 \\
\hline 9. ... eat fruit as a snack instead of a candy bar & 0.72 & 0.59 & $2 \cdot 73$ & $1 \cdot 16$ \\
\hline 10. ... eat fruit when eating together with my friends & 0.72 & -0.31 & $3 \cdot 46$ & $0 \cdot 81$ \\
\hline 11. ... eat fruit as a snack instead of crisps & 0.69 & 0.55 & $2 \cdot 67$ & $1 \cdot 18$ \\
\hline 12. ... eat two or more pieces of fruit per day & 0.67 & $0 \cdot 25$ & $2 \cdot 86$ & $1 \cdot 13$ \\
\hline 13. ... eat fruit in social situations, such as at a party, if it is available & 0.65 & $-0 \cdot 14$ & $3 \cdot 17$ & $1 \cdot 02$ \\
\hline 14. ... eat fruit as dessert after a hot meal & 0.64 & $-0 \cdot 18$ & $3 \cdot 20$ & $1 \cdot 04$ \\
\hline 15. ... remember to take fruit to school as snack & 0.64 & $0 \cdot 24$ & $2 \cdot 67$ & $1 \cdot 16$ \\
\hline 16. ... buy fruit if there is none in the house & 0.62 & -0.01 & $3 \cdot 14$ & $1 \cdot 08$ \\
\hline 17. ... ask someone in my family to buy fruit & $0 \cdot 45$ & $-0 \cdot 13$ & $3 \cdot 69$ & 0.63 \\
\hline Eigenvalue & $8 \cdot 55$ & $1 \cdot 43$ & & \\
\hline$\%$ Explained variance & $50 \cdot 3$ & $8 \cdot 4$ & & \\
\hline
\end{tabular}

†Response options were $1=$ uncertain, 2 = almost certain, $3=$ certain, 4 = very certain .

Table 3 Factor structure and item scores for the vegetable self-efficacy instrument

\begin{tabular}{|c|c|c|c|c|}
\hline \multirow{2}{*}{$\begin{array}{l}\text { Item } \\
\text { I am certain that I can... }\end{array}$} & \multicolumn{2}{|c|}{ Loadings } & \multirow[b]{2}{*}{ Mean scoret } & \multirow[b]{2}{*}{ SD } \\
\hline & Factor 1 & Factor 2 & & \\
\hline 1. ... eat vegetables as a snack & 0.83 & -0.33 & $2 \cdot 53$ & $1 \cdot 23$ \\
\hline 2. ... eat vegetables even if no one else is eating vegetables & $0 \cdot 81$ & 0.08 & $3 \cdot 01$ & $1 \cdot 06$ \\
\hline 3. ... eat vegetables during lunch & $0 \cdot 81$ & -0.05 & $2 \cdot 76$ & $1 \cdot 19$ \\
\hline 4. ... eat vegetables if I have to prepare them myself & $0 \cdot 81$ & -0.09 & $3 \cdot 03$ & $1 \cdot 09$ \\
\hline 5. ... eat vegetables if my parents are not there & $0 \cdot 80$ & $0 \cdot 22$ & $3 \cdot 23$ & 0.99 \\
\hline 6. ... eat vegetables when eating together with my friends & $0 \cdot 79$ & $0 \cdot 16$ & $3 \cdot 10$ & $1 \cdot 01$ \\
\hline 7. ... eat vegetables as a snack instead of a biscuit & $0 \cdot 78$ & -0.49 & $2 \cdot 18$ & $1 \cdot 23$ \\
\hline 8. ... eat vegetables in social situations, such as at a party, if available & $0 \cdot 77$ & -0.09 & $2 \cdot 75$ & $1 \cdot 17$ \\
\hline 9. ... eat vegetables as a snack instead of crisps & $0 \cdot 77$ & -0.48 & $2 \cdot 18$ & $1 \cdot 22$ \\
\hline 10. ... eat vegetables as a snack instead of a candy bar & $0 \cdot 76$ & -0.50 & $2 \cdot 19$ & $1 \cdot 21$ \\
\hline 11. ... remember to take vegetables to school as snack & $0 \cdot 76$ & $-0 \cdot 27$ & $2 \cdot 29$ & $1 \cdot 22$ \\
\hline 12. ... buy vegetables if there are none in the house & $0 \cdot 70$ & 0.08 & $3 \cdot 02$ & $1 \cdot 14$ \\
\hline 13. ... ask someone in my family to prepare vegetables for a hot meal & 0.66 & $0 \cdot 49$ & $3 \cdot 48$ & $0 \cdot 85$ \\
\hline 14. ... eat vegetables during a meal at home & 0.64 & $0 \cdot 45$ & 3.52 & $0 \cdot 87$ \\
\hline 15. ... eat four or more serving spoons of vegetables per day & $0 \cdot 61$ & 0.09 & $2 \cdot 88$ & $1 \cdot 11$ \\
\hline 16. ... ask someone in my family to buy vegetables & 0.59 & $0 \cdot 40$ & 3.52 & $0 \cdot 81$ \\
\hline 17. ... eat vegetables during a hot meal & 0.54 & 0.57 & $3 \cdot 65$ & $0 \cdot 74$ \\
\hline Eigenvalue & $9 \cdot 17$ & $1 \cdot 93$ & & \\
\hline$\%$ Explained variance & $53 \cdot 9$ & $11 \cdot 4$ & & \\
\hline
\end{tabular}

†Response options were 1 = uncertain, 2 = almost certain, $3=$ certain, $4=$ very certain . 
and 3). However, for the first factor, all factor loadings had a value of $>0 \cdot 40$. Moreover, only one item (in the VSE instrument) had a higher factor loading for factor 2 $(0.57)$ than for factor $1(0.54)$. On the basis of screeplots, one factor proved to be a suitable choice for both instruments. Both instruments can therefore be characterised as unidimensional scales, which means that both instruments measure a single construct. The first factor accounts for $50.3 \%$ of the variance in the FSE instrument and $53.9 \%$ of the variance in the VSE instrument.

\section{Internal consistency}

The Cronbach's $\alpha$ of the FSE instrument was 0.94 and of the VSE instrument $0 \cdot 95$. On the basis of the analysis of items at the item level, according to the ' $\alpha$ if item deleted' procedure, removing an item did not have a great influence on the $\alpha$ level (maximum increase of $0 \cdot 001$ ).

Further research on the inter-item correlation is required to properly interpret the high $\alpha$. A rough indication of the internal consistency of a unidimensional instrument is that the average inter-item correlation must be considerably higher than $0 \cdot 20$, and Cronbach's $\alpha$ must be at least $0 \cdot 75^{(39)}$. The average inter-item correlation of the FSE instrument was $0 \cdot 46$ and of the VSE instrument $0 \cdot 50$.

\section{Temporal stability}

Because the conditions in which the students completed the instruments for the second time varied, subgroups

Table 4 Test-retest reliability of the FSE and VSE instruments (completed in the classroom; ICC)

\begin{tabular}{ccc}
\hline & $\begin{array}{c}\text { In the classroom/ } \\
\text { started with the FSE } \\
\text { and VSE instrumentst } \\
(n 11)\end{array}$ & $\begin{array}{c}\text { In the classroom/ended } \\
\text { with the FSE and VSE } \\
\text { instruments } \\
(n \text { 47) }\end{array}$ \\
\hline FSE & $0 \cdot 84^{\star *}$ & $0.35^{\star *}$ \\
VSE & $0 \cdot 70^{\star \star}$ & $0.33^{\star}$
\end{tabular}

FSE, fruit self-efficacy instrument; VSE, vegetable self-efficacy instrument; ICC, intra-class correlation coefficient.

${ }^{*} P<0.05 ;{ }^{*} P<0.01$.

tQuestionnaire started with the FSE and VSE instruments and ended with the 'alcohol self-efficacy' instrument.

‡Questionnaire started with the 'alcohol self-efficacy' instrument and ended with the FSE and VSE instruments.

Table 5 Test-retest reliability of the FSE and VSE instruments (completed at the students' own initiative; ICC)

\begin{tabular}{lcc}
\hline & $\begin{array}{c}\text { Own initiative/started } \\
\text { with the FSE and VSE } \\
\text { instrumentst } \\
(n \text { 20) }\end{array}$ & $\begin{array}{c}\text { Own initiative/ended } \\
\text { with the FSE and VSE } \\
\text { instruments } \\
(n \text { 28 })\end{array}$ \\
\hline FSE & $0.70^{\star \star}$ & $0.41^{\star}$ \\
VSE & $0.57^{\star \star}$ & $0.47^{\star \star}$ \\
\hline
\end{tabular}

FSE, fruit self-efficacy instrument; VSE, vegetable self-efficacy instrument; ICC, intra-class correlation coefficient.

${ }^{\star} P<0.05 ;{ }^{*} P<0.01$.

tQuestionnaire started with the FSE and VSE instruments and ended with the 'alcohol self-efficacy' instrument.

‡Questionnaire started with the 'alcohol self-efficacy' instrument and ended with the FSE and VSE instruments.
Table 6 Predictive validity of the FSE and VSE instruments (Spearman's rank correlation)

\begin{tabular}{lcc}
\hline & FSE & VSE \\
$(n 462)$ & $(n 460)$ \\
\hline Fruit consumption & $0 \cdot 41^{* *} \dagger$ & $0 \cdot 26^{\star *} \ddagger$ \\
Vegetable consumption & $0 \cdot 27^{* \star} \ddagger$ & $0 \cdot 32^{\star *}+$ \\
\hline
\end{tabular}

FSE, fruit self-efficacy instrument; VSE, vegetable self-efficacy instrument. ${ }^{\star \star} P<0.01$.

tRefers to the level in which self-efficacy is positively correlated within the fruit behavioural domain or the vegetable behavioural domain ('generality').

\#Refers to the level in which self-efficacy is positively correlated between the fruit behavioural domain and the vegetable behavioural domain ('generality').

were formed for calculating the ICC. Students completed the instruments the second time in the classroom (Table 4) or at their own initiative (Table 5). A distinction was also made in the order in which the self-efficacy instruments were completed. As with the first test, students started either with the FSE and VSE instruments or with the 'alcohol self-efficacy' instrument. The ICC of the two selfefficacy instruments varied between 0.33 and 0.84 $(P<0 \cdot 05)$ in the subgroups.

\section{Predictive validity}

Spearman's rank correlations between FSE and consumption and between VSE and consumption varied between $0 \cdot 26$ and $0.41(P<0 \cdot 01$; Table 6$)$.

\section{Discussion}

The purpose of the present research was to test the reliability and validity of the developed FSE and VSE instruments for secondary-school students.

\section{Reliability}

Reliability is determined by calculating internal consistency and temporal stability. Both the FSE and VSE instruments display good internal consistency. The fact that the Cronbach's $\alpha$ of both instruments is very high $(>0.90)$ could indicate that a number of items pose the same question in a slightly different way ${ }^{(40)}$. Therefore, a reduction in the number of items is worth the benefit of lowering respondent burden. For example, the content of items 3, 7 and 14 of the FSE instrument (Table 2) seems to overlap with that of item 6 , and the content of items 5, 9 and 11 with that of item 1 . If these six items are removed, $\alpha$ is 0.90 . The content of items 3 and 17 of the VSE instrument (Table 3) seems to overlap with that of item 14 , and that of items 7,9 and 10 with item 1 . If these five items are removed, $\alpha$ is 0.93 . The final decision regarding the definite deletion of items of both instruments should be taken by the expert panel.

This is the first time that the stability of an FSE or VSE instrument is being studied for secondary-school students or for young people in this age group. The order in which the self-efficacy instruments were completed seems to 
have had a larger influence on stability than the method used to gather the data (Tables 4 and 5). The students who completed the 'alcohol self-efficacy' instrument first scored lower for the stability of the FSE and VSE instruments than the students who started with the FSE instrument. A possible explanation is that the students started to tire of the questionnaires, and were unable to concentrate properly on the last instruments ${ }^{(26)}$. However, it is important to mention here that there were not many students in the subgroups, and thus conclusions must not be drawn too hastily.

On the basis of the guidelines of Cichetti ${ }^{(37)}$, the ICC of the self-efficacy instruments used in the present research are fair to excellent for students who started by completing the FSE $(0.70$ and 0.84$)$ and VSE instruments $(0.57$ and $0 \cdot 70$ ). The ICC is poor to fair for students who completed the FSE $(0.35$ and 0.41$)$ and VSE instruments $(0.33$ and 0.47$)$ last.

\section{Validity}

Content validity, construct validity and predictive validity were all calculated. The content validity of both instruments was thoroughly examined by experts with knowledge of the concept of self-efficacy and fruit and vegetable consumption among young people. The content validity of the research would thus appear to be sufficiently safeguarded.

Research on the factors used in an FSE or VSE instrument among secondary-school students or young people in this age group has not been described previously in the literature. In previous research of 10-11-year-old primaryschool students ${ }^{(41)}$ and adults ${ }^{(42,43)}$, the FSE and VSE instruments were characterised as unidimensional, just as in the present research.

The predictive validity of both instruments is moderate. In comparison with the research by Neumark-Sztainer et $a l^{(21)}$ - the only study of secondary-school students that describes the correlation coefficient - the correlations in the present research are higher. In the research by Neumark-Sztainer et al. ${ }^{(21)}$, a correlation of $0 \cdot 18$ was found between the 'self-efficacy for making healthy dietary choices' and fruit and vegetable consumption.

It is striking that the present research is the first on secondary-school students in which self-efficacy is measured specifically for vegetables, and only the second in which it is measured specifically for fruit. Other studies measured such phenomena as 'self-efficacy for making healthy dietary choices'. It is possible that a relationship with fruit and vegetable consumption was not always found in earlier research among secondary-school students because of this.

The correlations in the present research are comparable with research on 10-12-year-old primary-school students ${ }^{(41,44-46)}$. The correlation between FSE and fruit consumption was 0.41 in the present research, whereas among primary-school students it varied between $0 \cdot 19$ and 0.42 . The correlation between VSE and vegetable consumption was 0.32 in the present research, whereas among primary-school students it varied between no correlation in one study and $0 \cdot 33$. These results suggest that the self-efficacy of secondary-school students does not have, or hardly has, more influence on fruit and vegetable consumption than the self-efficacy of primary-school students. These results also lead one to surmise that self-efficacy has an influence on fruit and vegetable consumption at an earlier stage than at secondary-school level. Another salient finding is that the relationship between FSE and fruit consumption is stronger than that between VSE and vegetable consumption. The explanation for this may be that young people have more influence on what they consume between meals, such as fruit, than on what they consume at main meal times, such as vegetables ${ }^{(44)}$.

On the basis of the poor correlation found between self-efficacy and fruit and vegetable consumption in the present research, it is debatable whether there is any value in designing interventions for increasing FSE and VSE. Self-efficacy increasing interventions may well have only a slight effect on fruit and vegetable consumption.

\section{Limitations}

Because the instruments were completed in the classroom, it is conceivable that the students influenced each other's choices. The students were spaced apart to prevent this as much as possible. During the completion of the instruments a second time, this 'separation' was not possible for seventeen classes. The students were allowed to decide for themselves where and when they would complete the instruments digitally. This has also influenced the number of responses negatively.

Furthermore, alongside the FSE and VSE instruments, the students also had to complete an 'alcohol self-efficacy' instrument. Because some students may have become demotivated after completing one or two instruments, this may have influenced the results.

Another limitation is that many ethnic minorities widely represented in the Netherlands were strongly underrepresented.

\section{Practical implications}

Both instruments can be used for researching self-efficacy as a determinant of fruit and vegetable consumption, and for evaluating the effects of nutrition education programmes on secondary-school students. The two instruments can be used independently or in combination. It is important not to offer too many instruments to the students at the same time, as this could influence the reliability of the results.

\section{Conclusion and recommendations}

The FSE and VSE instruments are sufficiently reliable and valid. The instruments can be used to measure FSE and VSE 
among Dutch secondary-school students. Further research, in which the predominant ethnic minorities in the Netherlands are sufficiently represented, is required to confirm this conclusion.

Despite the fact that increasing FSE and VSE can have a small effect on fruit and vegetable consumption, more research on the effect of self-efficacy increasing interventions is required to understand this better. Such experimental research can provide more evidence of a causal relationship than can cross-sectional research.

Furthermore, following research should preferably measure fruit and vegetable consumption by means of observation or ' $24 \mathrm{~h}$ recall' questionnaires ${ }^{(7)}$. This would allow more accurate measurement of consumption, and the relationship between consumption and self-efficacy could be more precisely studied.

\section{Acknowledgements}

The present research received no specific grant from any funding agency in the public, commercial or not-forprofit sectors. The authors have no conflict of interest. R.B. designed the study and carried out all aspects of data collection and statistical analyses; J.J.v.d.B. assisted with all aspects of the study. The authors thank the teachers and experts for their participation in the present research.

\section{References}

1. Summerbell CD, Water E, Edmunds LD et al. (2005) Interventions for preventing obesity in children. Cochrane Database Syst Rev, issue 3, CD001871.

2. van den Hurk K, van Dommelen P, de Wilde JA et al. (2006) Prevalentie van Overgewicht en Obesitas Bij Jeugdigen 4-15 Jaar in de Periode 2002-2004. Leiden: TNO.

3. Bulk-Bunschoten AMW, Renders CM, van Leerdam FJM et al. (2004) Signaleringsprotocol Overgewicht in de Jeugdgezondheidszorg. Amsterdam: Huisdrukkerij VUMC.

4. Breetvelt AM (2003) Overgewicht bij kinderen van Turkse en Marokkaanse afkomst. Epidemiologisch Bull 38, 24-27.

5. Verheul-Koot MA (2002) Achtergrondinformatie 'Terug naar de gezonde basis', Campagne ter preventie van overgewicht bij kinderen in Nederland. Oss: Nederlandse Vereniging van Diëtisten.

6. Renders CM, Seidell JC, van Mechelen W et al. (2004) Overgewicht en obesitas bij kinderen en adolescenten en preventieve maatregelen. NTvG 148, 2066-2070.

7. van Kooten M, de Ridder D, van Dorsselaer S et al. (2005) Hoe gezond eten Nederlandse scholieren? Bevindingen uit de Nederlandse HBSC-studie. TSG 83, 327-334.

8. Frenn M, Malin S \& Bansal NK (2003) Stage-based interventions for low-fat diet with middle school students. J Pediatr Nurs 18, 36-45.

9. Contento IR, Koch PA, Lee $\mathrm{H}$ et al. (2007) Enhancing personal agency and competence in eating and moving: formative evaluation of a middle school curriculumChoice, Control, and Change. J Nutr Educ Behav 39, 179-186.

10. Bandura A (1997) Self-Efficacy: The Exercise of Control. New York: W.H. Freeman and Company.
11. Bandura A (1986) Social Foundations of Thought and Action. A Social Cognitive Theory. Englewood Cliffs, NJ: Prentice Hall.

12. Marks R, Allegrante JP \& Lorig K (2005) A review and synthesis of research evidence for self-efficacy-enhancing interventions for reducing chronic disability: implications for health education practice (part I). Health Promot Pract 6, 37-43.

13. Maibach E \& Murphy DA (1995) Self-efficacy in health promotion research and practice: conceptualization and measurement. Health Educ Res 10, 37-50.

14. Bandura A (1991) Self-efficacy mechanism in physiological activation and health-promoting behavior. In Neurobiology of Learning, Emotion and Affect, pp. 229-269 [J Madden, editor]. New York: Raven Press.

15. O'Leary A (1995) Self-efficacy and health. Behav Res Ther 23, 437-451.

16. Strecher V, DeVellis BM, Becker MH et al. (1986) The role of self-efficacy in achieving health behavior change. Health Educ Q 13, 73-91.

17. Yalow ES \& Collins JL (1987) Self-efficacy in health behavior change: issues in measurement and research design. Adv Health Educ Promot 2, 181-199.

18. Bandura A (1977) Social Learning Theory. Englewood Cliffs, NJ: Prentice Hall.

19. Shortridge LM \& van der Bijl JJ (1996) International collaborative research on management self-efficacy in diabetes mellitus. JN Y State Nurses Assoc 27, 9-14.

20. Zabinski MF, Daly T, Norman GJ et al. (2006) Psychosocial correlates of fruit, vegetable, and dietary fat intake among adolescent boys and girls. J Am Diet Assoc 106, 814-821.

21. Neumark-Sztainer D, Wall M, Perry C et al. (2003) Correlates of fruit and vegetable intake among adolescents. Findings from Project EAT. Prev Med 37, 198-208.

22. Young EM, Fors SW \& Hayes DM (2004) Associations between perceived parent behaviours and middle school student fruit and vegetable consumption. J Nutr Educ Behav 36, 2-8.

23. Long JD \& Stevens KR (2004) Using technology to promote self-efficacy for healthy eating in adolescents. J Nurs Scholarsh 36, 134-139.

24. Martens MK, van Assema AP \& Brug J (2005) Why do adolescents eat what they eat? Personal and social environmental predictors of fruit, snack and breakfast consumption among 12-14-year-old Dutch students. Public Health Nutr 8, 1258-1265.

25. Mailvil LA, Lawson R, Horwath CC et al. (2009) Validates scales to assess adult self-efficacy to eat fruits and vegetables. Am J Health Promot 23, 210-217.

26. Polit DF \& Beck CT (2004) Nursing Research. Principles and Methods. Philadelphia, PA: Lippincott Williams \& Wilkins.

27. Lynn MR (1986) Determination and quantification of content validity. Nurs Res 35, 382-385.

28. Bandura A (1977) Self-efficacy: toward a unifying theory of behavioral change. Psychol Rev 84, 191-215.

29. Schaalma H (1993) De analyse van gedragsdeterminanten. In Gezondheidsvoorlichting en Gedragsverandering, pp. 134-167 [V Damoiseaux, HT Molen and GJ van der Kok, editors]. Assen: Van Gorcum.

30. van der Bijl JJ \& Shortridge LM (2001) The theory of measurement of the self-efficacy construct. Sch Inq Nurs Pract 15, 189-207.

31. Bandura A (2006) Guide for creating self-efficacy scales. In Self-efficacy Beliefs of Adolescents, pp. 307-337 [F Pajares and $\mathrm{T}$ Urdan, editors]. Greenwich: Information Age Publishing.

32. Thombs DL \& Heatey KR (1997) Fruit-Vegetable consumption self-efficacy in youth. Am J Health Behav 21, 172-177.

33. Baranowski T, Domel S, Gould R et al. (1993) Increasing fruit and vegetable consumption among 4 th and 5 th grade 
students: results from focus groups using reciprocal determinism. J Nutr Educ 25, 114-120.

34. Stokking KM (1998) Bouwstenen voor Onderzoek in Onderwijs en Opleiding. Utrecht: Capaciteitsgroep Onderwijskunde.

35. Vereecken CA \& Maes L (2003) A Belgian study on the reliability and relative validity of the Health Behaviour in School-Aged Children food-frequency questionnaire. Public Health Nutr 6, 581-588.

36. Polit DF \& Beck CT (2006) The content validity index: are you sure you know what's being reported? Critique and recommendations. Res Nurs Health 29, 489-497.

37. Cicchetti DV (1994) Guidelines, criteria, and rules of thumb for evaluating normed and standardized assessment instruments in psychology. Psychol Assess 6, 284-290.

38. Centraal Bureau voor de Statistiek (2009) Voortgezet Onderwijs; Deelname van de Leerlingen Naar Herkomstgroepering. Den Haag/Heerlen: CBS; available at http:// statline.cbs.nl/StatWeb/publication/?VW $=\mathrm{T} \& D M=S L N L \& P A=$ $71215 \mathrm{NED} \& \mathrm{D} 1=2-3 \& \mathrm{D} 2=\mathrm{a} \& \mathrm{D} 3=0 \& \mathrm{D} 4=0-2,7-9 \& \mathrm{D} 5=0-1,3-$ $4 \& \mathrm{D} 6=0 \& \mathrm{D} 7=0 \& \mathrm{D} 8=3-4 \& \mathrm{HD}=090218-1443 \& \mathrm{HDR}=$ $\mathrm{G} 2, \mathrm{G} 6, \mathrm{G} 5, \mathrm{~T}, \mathrm{G} 1, \mathrm{G} 7 \& \mathrm{STB}=\mathrm{G} 4, \mathrm{G} 3$

39. de Jonge J \& Hamers JPH (1997) De ontwikkeling en beoordeling van vragenlijsten. Verpleegkunde 12, 173-183.

40. Streiner DL \& Norman GR (1989) Health Measurement Scales: A Practical Guide to Their Development and Use. New York: Oxford University Press.
41. Thompson VJ, Bachman CM, Baranowski T et al. (2007) Self-efficacy and norm measures for lunch fruit and vegetable consumption are reliable and valid among fifth grade students. J Nutr Educ Behav 39, 2-7.

42. Ma J, Betts NM, Horacek T et al. (2002) The importance of decisional balance and self-efficacy in relation to stages of change for fruit and vegetable intakes by young adults. Am J Health Promot 16, 157-166.

43. de Vet E, de Nooijer J, de Vries NK et al. (2005) Determinants of forward stage transition from precontemplation and contemplation for fruit consumption. Am J Health Promot 19, 278-285.

44. Vereecken CA, van Damme W \& Maes L (2005) Measuring attitudes, self-efficacy, and social and environmental influences on fruit and vegetable consumption of 11- and 12-year-old children: reliability and validity. J Am Diet Assoc 105, 257-261.

45. de Bourdeaudhuij I, Klepp KI, Due P et al. (2005) Reliability and validity of a questionnaire to measure personal, social and environmental correlates of fruit and vegetable intake in 10-11-year-old children in five European countries. Public Health Nutr 8, 189-200.

46. Wind MPH, de Bourdeaudhuij I, te Velde SJ et al. (2006) Correlates of fruit and vegetable consumption among 11-year-old Belgian-Flemish and Dutch schoolchildren. J Nutr Educ Behav 38, 211-221. 